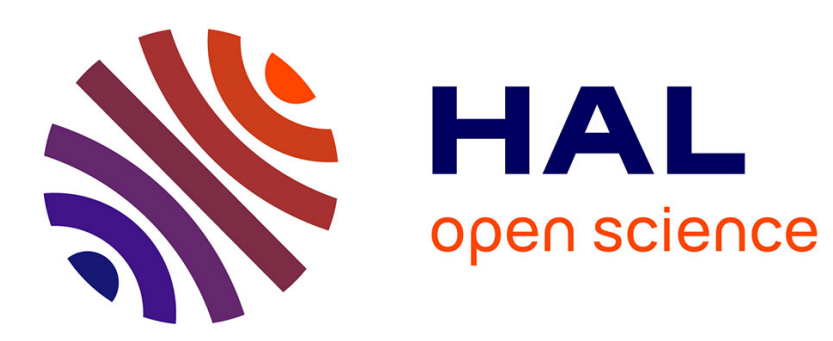

\title{
Stereotype endorsement and perceived ability as mediators of the girls' gender orientation-soccer performance relationship
}

\author{
Aïna Chalabaev, Philippe Sarrazin, Paul Fontayne
}

\section{To cite this version:}

Aïna Chalabaev, Philippe Sarrazin, Paul Fontayne. Stereotype endorsement and perceived ability as mediators of the girls' gender orientation-soccer performance relationship. Psychology of Sport and Exercise, 2009, 10, pp.297-299. 10.1016/j.psychsport.2008.08.002 . hal-00391199

\author{
HAL Id: hal-00391199 \\ https://hal.science/hal-00391199
}

Submitted on 3 Jun 2009

HAL is a multi-disciplinary open access archive for the deposit and dissemination of scientific research documents, whether they are published or not. The documents may come from teaching and research institutions in France or abroad, or from public or private research centers.
L'archive ouverte pluridisciplinaire HAL, est destinée au dépôt et à la diffusion de documents scientifiques de niveau recherche, publiés ou non, émanant des établissements d'enseignement et de recherche français ou étrangers, des laboratoires publics ou privés. 
1 Running head: STEREOTYPE ENDORSEMENT AND GIRLS' SOCCER PERFORMANCE

2

7

17 Correspondence concerning this article should be addressed to Aina Chalabaev or Philippe
Stereotype endorsement and perceived ability as mediators of the girls' gender orientation-soccer performance relationship.

\section{Aïna Chalabaev \& Philippe Sarrazin}

University of Grenoble, Laboratoire Sport et Environnement Social, France

Paul Fontayne

University of Paris-Sud 11, Laboratoire de Psychologie des Pratiques Physiques, France

Psychology of Sport and Exercise (2009), 10, 297-299.
8 Sarrazin, Laboratoire Sport et Environnement Social, UFRAPS, Université de Grenoble, BP 53, 38041 Grenoble Cedex 9, France. Tel: +33 476.63.50.97; Fax : +33 476.63.51.00. E-mail: aina.chalabaev@ujf-grenoble or philippe.sarrazin@ujf-grenoble.fr. Aïna Chalabaev is now at University of Nice Sophia-Antipolis. 
2 Objective: This study investigated girls' endorsement of the stereotype that girls are not good

3 soccer performers through three questions: (1) Did stereotype endorsement predict soccer

4 performance? (2) Was this relationship mediated by perceived ability? and (3) Was

$5 \quad$ stereotype endorsement related to gender role orientation?

6 Method: One-hundred-and-two junior high school girls from the 6th to the 9th grade (Mage $=$

$7 \quad 13.5$ years, $S D=1.23$ ) reported their beliefs about girls' and boys' performance in soccer,

8 perceived ability and gender role orientation. Next, their soccer performance was observed

9 during matches in compulsory physical education classes. A path-analytic model tested the

10 relationships among the variables using a product-moment correlation matrix and a maximum

11 likelihood estimation procedure.

12 Results: Stereotype endorsement (i.e., the belief that girls' performance in soccer is poor)

13 negatively predicted performance, this relationship being mediated by perceived ability.

14 Moreover, masculinity positively predicted perceived ability, and this relationship was

15 partially mediated by stereotype endorsement.

16 Conclusion: This study reinforces the idea that girls' sports performance may be related to

17 gender stereotypes. Interpretations of the results in light of Eccles et al.'s expectancy-value

18 model and stereotype threat theory are discussed, along with implications for practice.

20 Key words: Gender stereotypes; Stereotype endorsement; Sports performance; Perceived 21 ability; Gender role. 
Introduction

Although female sports participation has recently increased (e.g., Riemer \& Visio, 2003), boys perform still better in physical education (PE) classes (French Ministry of

4 Education, 2000). This may be due to the influence of the stereotype that many sports are masculine, which has been shown to affect perceived ability in sports (e.g., Fredricks \&

6 Eccles, 2005). However, although one may have knowledge of a cultural stereotype, his or her

7 personal beliefs may or may not be congruent with the stereotype (Devine, 1989). In other words, it is important to investigate stereotype endorsement in order to have a deeper understanding of the influence of gender stereotypes on sports performance, and this was the goal of the study.

A few research reported an effect of stereotype endorsement on perceived ability (e.g., Bonnot \& Croizet, 2007; Schmader, Johns, \& Barquissau, 2004), but only one study to our knowledge has investigated its effects on performance (Belcher, Lee, Solmon, \& Harrison, 2003): girls considering hockey as masculine performed lower than girls perceiving it as neutral. However, these latter girls watched a same-sex model proficiently executing the task, and this may have explained the results (e.g., Gould \& Weiss, 1981). A first goal of this study was to examine stereotype endorsement as a predictor of performance and the mediation of this relationship by perceived ability. Second, as research has shown that people who endorse the attributes considered as appropriate to their sex (e.g., women endorsing feminine attributes) are likely to assess the appropriateness of sports on a gender basis (e.g., Koivula, 21 1995), a second goal was to study masculinity (M) and femininity (F) as antecedents of 22 stereotype endorsement. The tested model is presented in Figure 1. 
One-hundred-and-two girls $($ Mage $=13.5$ years, $S D=1.2)$ from the $6^{\text {th }}$ to the $9^{\text {th }}$ grade

2 of three French junior high schools participated in this correlational study. Data were

3 collected in PE classes during compulsory soccer lessons, a sport perceived as masculine in

4 Europe (Koivula, 1995). Students filled out a questionnaire, and after a 10-minute warming

5 up, the teacher constituted three-player teams of same level students (i.e., high-level players

6 together and low-level players together). Next, students played four-minute matches based on

7 the "up-and-down" rule, which favours an equal rapport of strength: the fields were

8 numbered, and at the end of each game, the winning team "moved up" from for example field

$9 \quad \# 3$ to \#2, whereas the losing team “moved down". The experimenter, who was an experienced

10 soccer player and blind to participants' responses to the questionnaire, observed the players of

11 one team per game, each team being observed once.

12 Measures

Perceived ability in soccer was assessed by three items on a 7-point scale ranging

from (1) very poor to (7) very good (e.g., "I think that my level of performance in soccer is."), used by Duda and Nicholls (1992) and adapted to soccer $(\alpha=.74)$.

Stereotype endorsement was assessed with Bonnot and Croizet's (2007) measure, including two items relative to the level of soccer performance students personally assigned to girls and boys (e.g., "personally, I think that girls' performance in soccer is") on a scale ranging from (1) very poor to (7) very good. The order of these two items was counterbalanced. The more participants believed that girls' performance was poor controlling for boys' performance, the more they endorsed the stereotype.

Masculinity and femininity. Participants filled out the validated French short version for teenagers of the Bem Sex Role Inventory (Fontayne, Sarrazin, \& Famose, 2000) on a 7point Likert scale. Athleticism, leadership, and self-confidence compose the M orientation ( $\alpha$ $=.77)$. Tenderness and sensitivity to others compose the $\mathrm{F}$ orientation $(\alpha=.69)$. 
2 (1997) was used. Unlike standardized tests assessing only technical skills, this measure also

Soccer performance. A measure elaborated by Gréhaigne, Godbout, and Bouthier assesses tactical skills, indexing thus more accurately one's overall soccer ability. Four elements compose it: (1) offensive balls (OB): the successful passes to a partner; (2) successful shots on goal (SS); (3) conquered balls (CB): the balls intercepted or stolen from an opponent, and (4) lost balls (LB): the balls lost to the other team. The formula used to calculate performance was: $(\mathrm{OB}+\mathrm{SS}+\mathrm{CB}) /(10+\mathrm{LB})$. The more the index is positive, the higher the performance. Gréhaigne et al. (1997) showed a good interobserver reliability of this index between four raters (.90) using the intraclass correlation technique, and a good performance stability (.87) over a one-week period. They also reported a good concurrent validity, the index being related with a different soccer performance measure $(r=.74)$. In the current study some matches were videotaped on a random basis, and a second observer rated four teams (i.e., 12 students), representing approximately $10 \%$ of the sample. The intraclass correlation was very good (.92), showing a good interobserver reliability.

\section{Results}

A path-analytic model tested the presumed relationships among the variables with the EQS 6.1 program, using a product-moment correlation matrix and a maximum likelihood estimation procedure ${ }^{1}$. The adequacy of the proposed model $^{2}$ was evaluated using four indices: (a) the chi-square distribution under the null hypothesis, (b) the normal fit index (NFI; Bentler \& Bonett, 1980), (c) the comparative fit index (CFI; Bentler, 1990), and (d) the root mean square error of approximation (RMSEA). The adequacy of the model was good: $\chi^{2}(2)=1.59, p=.45, \mathrm{NFI}=.98, \mathrm{CFI}=1, \mathrm{RMSEA}=.00$. Figure 1 shows the standardised path coefficients. First, belief that girls' performance in soccer is poor $^{3}$ negatively predicted perceived ability $(\beta=-.26, p=.002)$, which significantly predicted performance $(\beta=.30, p=$ .002). Belief about girls' performance did not predict performance $(\beta=-.13, p=.18)$, after 
1 controlling for the effect of perceived ability, whereas the direct correlation between these

2 variables was significant $(r=-.21, p<.05)$. This suggests that perceived ability mediated this

3 relationship. Next, $M$ marginally predicted belief about girls' performance $(\beta=-.18, p=.07)$,

4 and significantly predicted perceived ability $(\beta=.44, p<.01)$ and belief that boys'

5 performance in soccer is good $(\beta=-.21, p=.04)$. This suggests that stereotype endorsement

6 partially mediated the relationship between gender role and perceived ability. Finally, the

7 analyses did not reveal any significant relationship involving $\mathrm{F}$.

\section{Discussion}

First, results showed that the more girls believed in the negative ingroup stereotype associated with soccer (i.e., that girls' performance is poor), the lower they performed, this relationship being mediated by a low perceived ability. These findings provide an extension to the literature by showing that stereotype endorsement may predict not only perceived ability, but also actual performance. They also demonstrate the role of perceived ability in the mediation of this relationship, reinforcing Eccles et al.'s expectancy-value model (e.g., Fredricks \& Eccles, 2005). These results may be understood in terms of a stereotype internalisation hypothesis: the exposure to cultural stereotypes during the socialisation process may lead some people to believe that the stereotypes are true for themselves, resulting in poor performance in the stereotyped domain (e.g., Bonnot \& Croizet, 2007).

$$
\text { Stereotypes may also affect performance in other ways. For example, a more }
$$
situational interpretation would be to consider the results in terms of stereotype threat (e.g., Steele \& Aronson, 1995): when a negative ingroup stereotype is made salient in a testing situation, people may fear confirming the stereotype, this extra pressure impeding their performance. A study recently showed that females may be susceptible to this effect in soccer (Chalabaev, Sarrazin, Stone, \& Cury, 2008). However, stereotype threat is not supposed to affect perceived ability (e.g., Steele \& Aronson, 1995, Study 1), but instead to create an 
1 "interpretative framework" that when difficulty is experienced during the task, it reduces self-

2 efficacy, which may evolve during the task and is thus a more situation-specific self-

3 assessment than perceived ability (Ryan \& Ryan, 2005). In this study we did not examine

4 girls' self-efficacy during the task, but rather their perception about their general soccer

5 ability prior to the evaluation. In sum, if Eccles et al.'s expectancy-value model seems to be

6 more appropriate to interpret our results, it is important to note that stereotypes may affect

7 performance in many ways that may add up to each other. It would be interesting to

8 distinguish in future studies the gender stereotypes effects due to stereotype internalisation

9 from the effects due to the presence of stereotypes in the social context.

Next, results showed that $\mathrm{M}$ negatively predicted stereotype endorsement, but not $\mathrm{F}$.

11 According to the differentiated additive androgyny model (e.g., Marsh \& Byrne, 1991), the

contribution of $\mathrm{M}$ is more important in masculine domains whereas the contribution of $\mathrm{F}$ is

more important in feminine domains. This idea has been corroborated in the sports areas (e.g.,

14 Guillet, Sarrazin, Fontayne, et Brustad, 2006), and could thus explain why F did not affect

15 stereotype endorsement and perceived ability in soccer.

Although this research reveals both some consequences and antecedents of stereotype endorsement, the results need to be considered with care. As with all path analytic studies, it is always possible that a relevant variable was omitted. Also, we cannot talk about causal relations between the variables: indeed, symmetrical relations may exist. For example, based on the identity bifurcation theory (Pronin, Steele, \& Ross, 2004), identification to soccer (i.e., non-endorsement of the stereotype) may lead to the depreciation of feminine characteristics in favour of masculine ones.

To conclude, this study reinforces the idea that girls' poor performance in PE classes

24 is in part due to the influence of gender stereotypes and highlight the role of personal beliefs in this relationship. This implies that it could be useful to design intervention programs based 
Stereotype endorsement and soccer performance 7

1 on changing girls' perceptions about gender appropriateness of sports in order to enhance 2 their performance in masculine sports. 
2 Belcher, D., Lee, A., Solmon, M., \& Harrison, L. (2003). The influence of gender-related

\section{References} beliefs and conceptions of ability on women learning the hockey wrist shot. Research Quarterly for Exercise and Sport, 74, 183-192.

Bentler, P. M. (1990). Comparative fit indexes in structural models. Psychological Bulletin, $107,238-246$.

Bentler, P. M., \& Bonett, D. G. (1980). Significance tests and goodness-of-fit in the analysis of covariance structures. Psychological Bulletin, 88, 588-606.

Bonnot, V., \& Croizet, J.-C. (2007). Stereotype internalization and women's math performance: The role of interference in working memory. Journal of Experimental Social Psychology, 43, 857-866.

Chalabaev, A., Sarrazin, P., Stone, J., \& Cury, F. (2008). Do achievement goals mediate stereotype threat? An investigation on females' soccer performance. Journal of Sport \& Exercise Psychology, 30, 143-158.

Devine, P. G. (1989). Stereotypes and prejudice: Their automatic and controlled components. Journal of Personality and Social Psychology, 56, 5-18.

Duda, J., \& Nicholls, J. (1992). Dimensions of achievement motivation in schoolwork and sport. Journal of Educational Psychology, 84, 1-10.

Fontayne, P., Sarrazin, P., \& Famose, J.-P. (2000). The Bem Sex-Role Inventory: Validation of a short-version for French teenagers. European Review of Applied Psychology, 50, 405-416.

Fredricks, J. A., \& Eccles, J. S. (2005). Family socialization, gender, and sport motivation and involvement. Journal of Sport and Exercise Psychology, 27, 3-31.

French Ministry of Education (2000). Les Epreuves du Baccalauréat en Education Physique et Sportive. Rapport de l'Inspection Générale. [High school diploma in physical 

education].ftp:/trf.education.gouv.fr/pub/edutel/syst/igen/baceps.pdf.

2 Gould, D., \& Weiss, M. (1981). The effects of model similarity and model talk on selfefficacy and muscular endurance. Journal of Sport Psychology, 3, 17-29.

Gréhaigne, J.-F., Godbout, P., \& Bouthier, D. (1997). Performance assessment in team sports. Journal of Teaching in Physical Education, 16, 500-516.

Guillet, E., Sarrazin, P., Fontayne, P., \& Brustad, R. (2006). Understanding female sport attrition in a stereotypical male sport within the framework of Eccles' s expectancyvalue model. Psychology of Women Quarterly, 30, 358-368.

Koivula, N. (1995). Ratings of gender appropriateness of sports participation: Effects of gender-based schematic processing. Sex Roles, 33, 543-557.

Marsh, H. W., \& Byrne, B. M. (1991). Differentiated additive androgyny model: Relations between masculinity, femininity and multiple dimensions of self-concept. Journal of Personality and Social Psychology, 61, 811-828.

Pronin, E., Steele, C. M., \& Ross, L. (2004). Identity bifurcation in response to stereotype threat: Women and mathematics. Journal of Experimental Social Psychology, 40, 152168.

Riemer, B., \& Visio, M. (2003). Gender typing of sports: An investigation of Metheny's classification. Research Quarterly for Exercise and Sport, 74, 193-204.

Ryan, K. E., \& Ryan, A. M. (2005). Psychological processes underlying stereotype threat and standardized math test performance. Educational Psychologist, 40, 53-63.

Schmader, T., Johns, M., \& Barquissau, M. (2004). The costs of accepting gender differences: The role of stereotype endorsement in women's experience in the math domain. Sex Roles, 50, 835-850.

Steele, C. M., \& Aronson, J. (1995). Stereotype threat and the intellectual test performance of African Americans. Journal of Personality and Social Psychology, 69, 797-811. 
Stereotype endorsement and soccer performance 10

Footnotes

2 1. The correlation matrix is available from the first author of the article.

3 2. Different models were also tested but not reported in the paper. For example, the

4 direct relations between $\mathrm{M}, \mathrm{F}$ and performance were formulated, but the paths between these

5 variables were not significant $(t \mathrm{~s}<|1.09|$ ). Thus, this model is not discussed any further.

6 Moreover, the interaction between $\mathrm{M}$ and $\mathrm{F}$ was not significantly related to the other variables

7 and was thus not included in the model tested in this study.

8

3. In order to clarify the interpretations, the response to the belief about girls'

9 performance item was reversed.

10 
Stereotype endorsement and soccer performance 11

2 Figure 1. Results of the path analysis model testing the relationships between the variables of 3 the study. 
Figure 1.

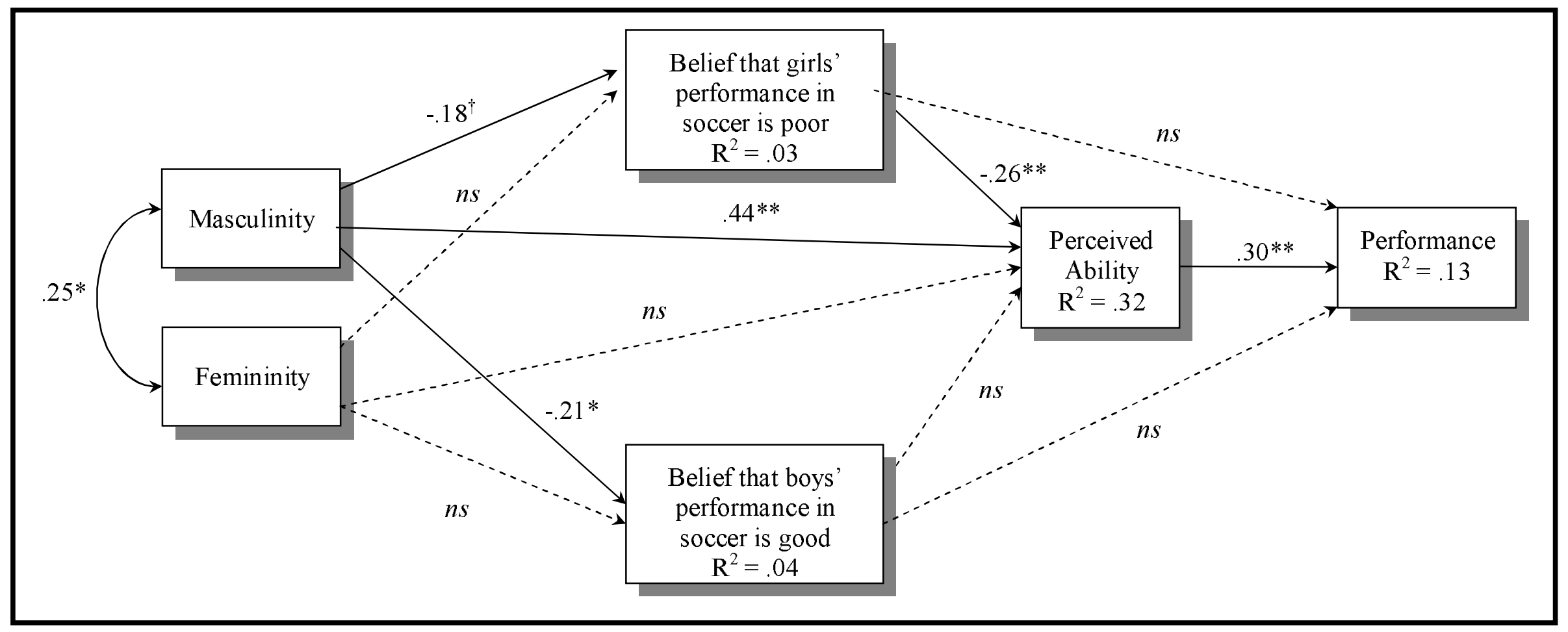

Note. ${ }^{\dagger} p<.10 ; * p<.05 ; * * p<.01$. 